\title{
RESEARCH ON THE STRATEGY OF INDUSTRIAL HERITAGE PROTECTION AND RENEWAL
}

\author{
Shangbo Gu ${ }^{1}$, Huayu Meng ${ }^{2}$ \\ ${ }^{1}$ School of Architecture, Nanjing Tech University, Dingshan Street, Nanjing 210000, China \\ ${ }^{2}$ School of Architecture, Nanjing Tech University, Dingshan Street, Nanjing 210000, China
}

KEY WORDS: Industrial heritage, Protection, Renewal

\begin{abstract}
In the post industrial era, with the development of urban economy and the upgrading of industrial structure, a large number of industrial enterprises in the city transfer from the city centre to the periphery of the city in order to relieve the pressure of urban land shortage and seek their own development. Therefore, the idle land left behind is favoured by the real estate development and emerging industries. As an important space carrier for the continuation of urban context and economic development, the industrial buildings left behind are very popular. Its protection and reuse are related to the development of regional economy and the revival of culture. Under the background of urban renewal, how to properly protect and update the modern industrial heritage to realize the organic integration of the new and old system has become an important topic of heritage protection in China.
\end{abstract}

Today, the transformation of industrial heritage is in full swing. Although the research in the field of industrial heritage in China has started relatively late and the domestic practical experience and related research depth are not enough to form a complete theoretical system, the society has reached a common sense of the protection and renewal of industrial heritage. In January 2018, the first batch of China's industrial heritage protection list was officially released, making China's industrial heritage protection and renewal more scientific and standardized, combining with urban renewal to promote the rapid development of modern urban culture and economy, environmental protection and resource utilization.

From the point of view of "protection and renewal", the paper summarizes the different value cognition of industrial building heritage, and discusses the relationship between the protection and reuse of industrial building heritage, and studies the relevant strategies for the protection and reuse of industrial building heritage, so as to provide reference for the research and development of other industrial building heritage.

\section{Introduction}

At present, China is in the development stage of urban stock renewal characterized by both social and economic development and urban cultural continuity, and the shortcomings of the construction and layout of many traditional industrial cities are becoming more and more prominent, and the former prosperous industrial buildings and their locations have become the main objects of old city renewal. So the protection and renewal of industrial heritage has become an important issue that needs urgent attention in heritage conservation and urban development. On the one hand, industrial heritage, as the remnants of human industrial civilization and urban industrial development, has inherent values of history, culture and art, and its protection is an important part of the continuation of urban culture. On the other hand, the loss of original functions, different degrees of damage and industrial pollution left behind make these industrial heritages gradually become abandoned areas of the city and empty areas of urban development. Only by renewing these buildings and re-integrating them into the planning process of urban development can we better achieve the goal of comprehensive and sustainable urban development. However, the renewal of industrial heritage will inevitably bring new requirements for new functions and new uses, which will inevitably form a certain contradiction with the protection of heritage. Therefore, this paper summarizes the different value cognition of industrial heritage from the perspective of " protection and renewal", discusses the relationship between protection and renewal, and lists the relevant strategies in the protection and renewal of industrial heritage, so as to provide reference for the protection and renewal of other industrial heritage.

\section{Value cognition of industrial heritage}

As a material carrier, industrial heritage has witnessed the historical development of human industrial civilization and urban industrial technology. Like those magnificent ancient temples and palaces, it is a living fossil of human history and urban development. It also has inherent values of history, culture and art. At the same time, compared with other cultural heritages, industrial heritage has a more distinct and broader realistic reuse value.

\subsection{Intrinsic value}

Since the Industrial Revolution in the 18th century, the rapid development of industry as the leading industry in the city has changed people's lives and also changed the face of the city, forming a unique human landscape and place connotation in the industrial era. Some of the industrial buildings and areas left to this day are the best exhibits of the city's industrial history as "city museums", which are also the evidence of the continuous development of society. In some coastal cities in China, the industrial buildings left over in history have become an important part of the human landscape of the city nowadays, and even an important landscape landmark of the city. In addition, the industrial buildings left over in different eras often 
show different characteristics in terms of style, material, scale, color, structure, etc. They are like "specimens" left over in the industrial age, which has important research value for us to study the social development, cultural orientation, scientific and technological level and architectural concept of the industrial age.

\subsection{Realistic reuse value}

Because industrial buildings often have special requirements for use functions and building spaces, which require special and more advanced technical means to meet the needs, most industrial buildings have stable structures and solid walls, so the material life of the building is usually longer than its initial functional life, thus making some industrial buildings have to face the reality of assuming different functions during the whole life cycle of the building. In the current stage of urban construction, which is dominated by stock renewal, many industrial heritage buildings are still within their physical life, but their original functional life has already ended, so giving them new functional requirements and renewing the building use function again is an important option for our urban development,which meets the requirements of sustainable development of resources and organic renewal of cities, and contributes to the further transformation and development of our cities.

\section{Cognition of the relationship between conservation and renewal}

\subsection{The contradictory relationship between the two}

The inherent value of industrial heritage, as the essential property of industrial heritage, is not influenced by external factors, and the inherent value of historical, cultural, social, technological and aesthetic aspects is the key to determine whether the architectural remains of the industrial age can rise to the level of heritage.The realistic reuse value of industrial heritage is often based on its inherent value, and is the development and utilization of inherent value, which usually needs to take into account the needs of different groups and the constraints of various external conditions. Therefore, the realistic reuse value of indus heritage does not reflect its full inherent value, and there is sometimes a contradiction between the choice of realistic reuse value and the protection of inherent value, and this contradiction is more intuitively expressed in the conflict between protection and renewal in urban regeneration.

\subsection{The attitude to be held towards both}

We should learn to examine the conflicting issues between protection and renewal from the perspective of scientific rationality.In the context of sustainable development, the renewal of industrial heritage has become an important link in the process of urban stock renewal. Compared with other historical buildings, industrial heritage has a more obvious and extensive realistic reuse value.The adoption of scientific and reasonable redevelopment means is not only the deep excavation and effective reuse of industrial heritage resources, but also the protection and manifestation of the original historical, cultural and artistic inherent values of the buildings.

Just as the most effective way to preserve a drop of water is to put it into the sea, the industrial buildings left over by history, which were originally an important part of the urban landscape, are gradually reduced to abandoned sections of the city and empty areas of urban development because of the loss of their original functions. Only by focusing on those industrial buildings that are about to be abandoned or have been abandoned, and using corresponding development and utilization measures to give these industrial buildings new urban functions, so that they can be integrated into the blueprint of urban development again, can we create conditions for the preservation of the historical and cultural values of these industrial buildings themselves, and help the remains rise to the level of heritage and enhance the cultural heritage of the city. As some industrial heritage has been protected, its inherent value represented by history and culture has been fully preserved, but as far as the value of such consciousness as history and culture is concerned, mere preservation is not enough. What we need is to inherit, carry forward, innovate and develop. Just as the best way to protect excellent traditional culture is to continuously inject vitality into it, so the best way to protect the multiple inherent values of industrial heritage is to renew them scientifically and reasonably.

At the present stage, there are various models for the renewal of industrial heritage in China, and the "urban industrial museum" has been adopted and developed by many provinces and cities as a typical way to protect and renew industrial heritage. This model has achieved a good balance between the protection and renewal of industrial heritage in the process of renewal of old industrial cities and form a relatively good development cycle. By giving urban exhibition nature to industrial buildings that have lost their use function, the original historical and cultural value is developed and reused, and converted into urban tourism resources, so as to promote the transformation of urban industrial structure. Part of the economic benefits are put into the follow-up work of industrial heritage protection, which constructs a long-term good development framework for the protection and renewal of industrial heritage. Therefore, the protection and renewal of industrial heritage are two complementary tasks. The effective protection of the inherent value of heritage lays a solid development foundation for the development and reuse of heritage. The scientific and reasonable renewal of heritage creates excellent external conditions for the protection and development of inherent value of heritage.

\section{Approach to industrial heritage preservation and renewal}

Generally speaking, the plane layout of industrial heritage is mostly square, the structural bearing capacity is high, and the architectural space has strong integrity and plasticity. "How the environmental advantages and spatial potential can be expressed and tapped out, and injected with new vitality, this is what the design should focus on". On the basis of the original structure system of the building,the transformation of space should fully explore the original spatial characteristics of the building, combine different types of functional replacement, shape a variety of spatial forms, and give the old industrial buildings rich spiritual and cultural connotations. There are various methods to transform the space of old industrial buildings, mainly divided into two categories:internal space remodeling and external expansion. 


\subsection{Remodeling of the interior spaces}

4.1.1 Space Separation: The method of space separation is generally used for long-span industrial buildings. Modern longspan industrial buildings are usually divided into upper and lower floors. The first floor is supported by structural columns, and the second floor is a large-span space without columns. On the basis of the original space form and volume, the interior space is separated into several unit spaces of appropriate scale by using light partition walls separated from the main structure to meet the needs of each function. On the premise of meeting the new functions, the transformation pays attention to the coordination between the original building structure and the new components.

4.1.2 Space Placement: It is an effective way to reorganize the space by inserting a new functional space into the original space, which is independent of the original structural system. This independent double structure system can maintain the original appearance of the building to the greatest extent.

\subsection{External space additions}

The old industrial buildings need to be partially demolished and added in the renovation and utilization, or the independent old space is connected to form a whole through the addition. In addition, we should not only consider the functional requirements of the added part, but also make a good connection and transition between the old and new buildings in terms of space, shape system and material selection. We should not only respect the original architectural style and space, but also fully show the characteristics of the added part, so as to inject new vitality into the old buildings.

4.2.1 Complementary isomorphic materials: isomorphic materials are used to continue the old industrial building form or supplement the old industrial form, so as to coordinate the old and new buildings. This method focuses on the continuity of the old and new buildings and emphasizes the reproduction of the original architectural symbols.

4.2.2 Contrast of heterogeneous materials: the use of heterogeneous materials for the additions is mainly to emphasize the differences between the old and new buildings in different periods. The old buildings often have solid and thick walls, single shape and full sense of history. The addition part uses light and transparent new materials, which makes the old and new buildings in the same environment in a dynamic balance, highlights the traces of history, and expresses the continuity and historicity of the building.

\section{Strategies related to protection and renewal}

\subsection{Build an evaluation system and promote protection by grades}

The protection of industrial heritage does not mean the indiscriminate protection of all historical industrial buildings. It is more important to conduct a detailed investigation and study of industrial buildings before the protection work, to fully understand their inherent value, and to evaluate the overall value of their heritage in combination with their reuse value, which can be divided into three categories: "high quality", "average" and "poor". The evaluation results can be divided into three categories: "high quality", "average" and "low quality", which can be permanently preserved, protected and revitalized, and demolished as appropriate. Only through rational understanding of the overall value of industrial heritage and objective evaluation and grading can we promote the conservation of industrial heritage with high quality and efficiency, and promote the high quality development of urban stock renewal.

\subsection{Step-by-step approach to preserve room for development}

Compared with other historical and cultural heritage, industrial heritage, as a special form of heritage, has more distinct material reuse value and more diversified development direction and model. The vast development space of industrial heritage also brings about conflicts in protection and renewal.For example, in some areas, due to the weak concept of conservation, some pioneers of architecture or art have been allowed to make a "facelift" or "drastic" transformation to the industrial heritage without considering the value of the heritage itself and make it an experimental object to show artistic charm and a performance field to show personal talent. Some regions, in the process of renewal, only take into account the immediate economic benefits and do not consider the limit of industrial heritage for transformation, blindly and roughly transforming the construction, making industrial heritage into a commercial flavor of office or entertainment places, losing the historical and cultural characteristics of their own buildings.

None of the above phenomena is a quality reflection of the concept of sustainable development in urban stock renewal. Sustainable development is the discovery and reuse of the value of things, and it is a gradual process, not explosive and instantaneous. For the sustainable development of industrial heritage, it represents both the exploration and protection of the original industrial history and cultural values, and the development process of industrial buildings leaving room for development, which can guarantee long-term use and make the civilization of multiple eras integrate in the same building. Therefore, the conservation and renewal of industrial heritage should strike a balance between protectionism and radical development, and seek a new development model to free industrial heritage from being a gimmick to attract tourists and a means for capital to make profits, so as to return to the protection and respect of the heritage itself.

\subsection{Government-led, public participation}

In the preliminary work of industrial heritage survey, registration and rating, the government must formulate corresponding guiding policies to ensure that the valuable industrial heritage can be registered smoothly after the rating is determined through the evaluation system. In the subsequent process of protection and reuse, a series of contradictions in property rights, changes in land use properties and restraints on developers require government departments to be in a leading position, so as to ensure that industrial heritage protection and renewal measures can be carried out smoothly. As the main users of industrial heritage, urban residents must be fully considered in the process of determining the development model of the heritage, in order to inject new vitality into the industrial heritage and thus achieve the purpose of promoting urban renewal. 


\section{Summary and conclusion}

As heritage, the inherent value of industrial heritage in history, culture, art and society is of great significance. As for architecture, its internal space has profound development potential. As a heritage as a whole, the development of its inherent value and the reuse of the building have an important role in promoting the preservation of urban landscape, the continuation of urban cultural lineage and the transformation of urban industrial structure. Therefore, it is necessary to look at the contradictory relationship between protection and renewal of architectural heritage in a scientific and rational way. Protection and renewal are not tit for tat, because drastic changes can be considered a kind of destruction to a certain extent, while total preservation type of protection is a sign of stubbornness. The development of industrial heritage should be based on the premise of preserving the inherent value of the building, enhancing the quality of the building and improving the spatial conditions, organically combining protection and renewal, focusing on long-term sustainable development, taking "protection" as the basis, looking for the development direction of "renewal", and using "renewal" as the basis. We should take "protection" as the basis, find the development direction of "renewal", and use the means of "renewal" to finally achieve the goal of "protection".

\section{REFERENCES}

$\mathrm{Wu}$ Liangyong. Turn-of-the-century gaze: the future of architecture [M]. Beijing: Tsinghua University Press, 1999

Jiang Nan, Wang Jianguo. Comprehensive evaluation of modern architectural heritage conservation and reuse [M]. Nanjing: Southeast University Press, 2016

Wang JG, Jiang N. Conservation and reuse of industrial historical building heritage in post-industrial China [J]. Journal of Architecture,2006(08):8-11.

Jane Jacobs. The Death and Life of Great American Cities [M] Translating Forest Press, 2005

Wang Jianguo . Urban Design [M]. Third Edition. Nanjing: Southeast University Press, 2011: 189

Liu Boying. An overview of the development of industrial building heritage conservation $[\mathrm{J}]$. Journal of Architecture, 2012, 01: 12-17

Bekker, P.C.F. A Life Cycle Approach in Building [J].In Building and Environment, Vol. 17, No. 1, 1982: 55-61

Lu Di. The Life and Death of Architecture - A Study on the Reuse of Historic Buildings [M]. Nanjing: Southeast University Press, 2004

Jean-Yves Andrieux, Le Patrimoine Industrial [M], Presses Universitaires de France, 1992

Patrick DAMBRON, Patrimoine Industrial \& Development Local [M].Paris: Editions Jean Delaville, 2004
Eleanor Conlin Casella, James Symonds, Industrial Archaeology: Future Directions [M], New York: Editions Springer Science+Business Media, 2005. Media, 2005

$\mathrm{Lu}$ Shao-Ming. On the conservation and reuse of urban industrial heritage [J]. Planner, 2006(10):13-15

Wei Longwu, Lu Zhitao, Guo Tong. Building Assessment, Reinforcement and Renovation [M]. 2nd edition. Nanjing: Jiangsu Science and Technology Press, 2006

Que Wei-Min. Traditional Chinese Industrial Heritage in the Perspective of World Heritage [J]. Economic Geography, 2008 (6): 1040-1044

Wang Jianguo. Conservation and renewal of industrial architectural heritage in the post-industrial era [M]. Beijing: China Construction Industry Press, 2008

Liu Boying. Sustainable development of urban existing industrial resources [J]. World Architecture, 2016 (4): 24-29

Liu Boying,Li Kuang. Study on the system of conservation and reuse of industrial building heritage in Beijing[J]. Journal of Architecture,2010(12):1-6.

Feng Lixing. Some issues on the research and protection of industrial heritage $[\mathrm{J}]$. Journal of Harbin Institute of Technology, 2008 (3): $1-8$

Liu Boying. The confusion over and re-understanding of industrial heritage [J]. Architectural heritage, 2017 (1): 8-17

Liu Boying, Li Kuang. Shougang industrial heritage conservation planning and renovation design [J]. Industrial Architectural Heritage, 2012 (1): 30-35

Liu Fuying. Research on the classification system of modern industrial heritage in China [J]. Urban Development Research, 2015 (11): 64-71

Liu B. Y. A review of the development of industrial building heritage conservation [J]. Journal of Architecture, 2012 (1): 12 17

Zeng Shan. The Historical Facts of Modern Chinese-Foreign Joint Ventures Questioned by Academic Monthly [J]. 1985 (7): $12-13$

Zhang Yanshen. The history of Japan's invasion of China by using the so-called "joint ventures" [M]. Shanghai: Sanlian Bookstore, 1958

Liu Boying. Exploring the core values of China's industrial heritage [J]. World Heritage, 2015(7):26 -32

Zhang Bochun. The transfer of Soviet technology to China [M]. Jinan: Shandong Education Publishing House, 2007

Zhen Xuefeng. Integrity of Cultural Heritage and Holistic Conservation Approach [D]. Shanghai: Tongji University, School of Architecture and Construction Planning, 2007

Wang Jianguo. Conservation and renewal of industrial architectural heritage in the post-industrial era [M]. Beijing: China Construction Industry Press, 2008: 47 
Liu $\mathrm{Yu}$. Research on the protection and reuse strategy of industrial architectural heritage in China in the post-industrial era [D]. Tianjin: Tianjin University, 2015

Liu Boying, Chen Hui. At the forefront of ecological revival ecological measures in the Ruhr industrial area of Germany [J]. Urban Environmental Design, 2007 (7): 24 -27

Pan Gu Xi. The History of Chinese Architecture [M]. China Construction Industry Press, 2004

Fang Thu. Assessment of China's non-heritage architectural heritage [D]. Southeast University Press, 1998

Du Dong, Pun Qinghua, Wu Yan. Modern Comprehensive Rating Methods and Selected Cases [M]. Beijing: Tsinghua University Press, 2008

Zhou Hongbo, Yao Hao. Fuzzy Comprehensive Evaluation of Sustainable Transformation and Utilization of Urban Existing Industrial Buildings [J]. Modernization of Construction Management, 2008 (6)

Qiu Junping, Wen Tingxiao, et al. Theoretical and methodological practice of evaluation [M]. Beijing: Science Press, 2010

Li Xin. Research on the design of restoration and reuse of modern industrial heritage building monoliths (1840-1910) [D]. Tianjin: Tianjin University, 2015

Fang Lixin, Zhou Qi. Technological Evolution Manifold in Historical Buildings - Analysis of the Zhang-string Structure of the Machine Factory of Jinling Machine Manufacturing Bureau [J]. Chinese Cultural Heritage, 2017 (3): 96-99

Yang Changming, Lan Wei. Technical strategies for restoration of modern historical buildings based on analysis of the mechanism of salvage - an example of restoration design of the former Zhejiang Xingye Bank building in Tianjin [J]. Journal of Architecture, 2015 (2): 55-59

Nie Wugang, Meng Jia. Industrial heritage and legal protection [ M]. Beijing: People's Court Press, 2009

Huang Q. Conservation and Reuse of Modern Industrial Buildings in Shanghai [D]. Shanghai: Tongji University, 2007

Zhang Yisan, Xia Jian. Shaping the regenerated urban cells: A study on the conservation and reuse of urban industrial heritage[J]. Urban Planning,2008(02):22-26

Jiang Nan. Techniques and methods for evaluating the value of industrial heritage based on adaptive reuse[J]. New Architecture, 2016(03):4-9

Wang Xueyong,Zhang Yongchao. Research on the protection and regeneration of industrial heritage based on urban cultural heritage[J]. Industrial architecture,2017,47(12)

Xia J, Wang Y. Research on integrated underground space development of industrial heritage lots in old cities based on overall protection[J]. Huazhong Architecture,2016,34(04):1114.
Luo WJ. Sustainable reuse practices and inspiration of industrial building heritage in Britain[J]. World Architecture,2019(06) 